\title{
EXTENDED APPROACH TO OPTIMIZE MODULAR PRODUCTS THROUGH THE POTENTIALS OF ADDITIVE MANUFACTURING
}

\author{
K.-E. W. H. Steffan ${ }^{凶}$, M. Fett and E. Kirchner \\ Technische Universität Darmstadt, Germany \\ $\triangle$ steffan@pmd.tu-darmstadt.de
}

\begin{abstract}
In modular products conflicting objectives may occur. This leads to characteristics as componentdependent oversizing and undersizing as well as increased complexity of the interfaces. These conflicts can be resolved using the potentials of AM processes. For the best use possible, the potentials are systematically considered in the early design phases as part of an extended procedure. The extended procedure improves the benefit-effort ratio of modular respectively individual products and a further optimization of the product architecture and consideration of synergy effects is achieved.
\end{abstract}

Keywords: design for x (DfX), design methods, modularisation, early design phase, additive manufacturing

\section{Introduction}

For years the transition from the seller's to the buyer's market has led to an increased adaptation of products to ever smaller groups of buyers. This results in the demand for more adaptable products and thus for a growing variety of products. At the same time greater customer proximity, e.g. through individual products are steadily becoming more important (Lissautzki, 2008). The economic provision of the growing variety of products increasingly poses challenges for companies. This situation is exacerbated by ever faster technological developments and the growing number of functions provided. Modularization is utilized to control the complexity due to the growing number of variants. According to Göpfert, modularisation is understood as the creation of a product architecture with components which are as functionally and physically independent as possible (Göpfert, 1998). Strategies of modularization can consist of reducing product variety, lowering complexity and configuring instead of constructing new variants. In the practical application the desired product variants are provided by configuration of existing modules. This has a distinct time average with appropriate stock keeping. These time advantages result from the elimination of the design and production process for modules in each variant. Conflicts arise in the defining and designing of the modules which are connected by interfaces. An example for this is the conflict between standardization and optimization for the specific requirements. In certain variants, this conflict leads to over- or undersized components (Krause and Gebhardt, 2018) and to complex interfaces which represent a possible weak point. Interfaces remain with optimization of the specific module and it is more advantageous to bypass interfaces (Kipp et al., 2010). It follows that the goal of modularization is to provide the required product variety with as few modules as possible. 
An example is integrating functions into existing function carriers or combining modules. This eliminates the need for individual components and the intermediate interface.

However, the design of individual variants can never be completely circumvented in practice. Feldhusen and Grote distinguish between adaptive modules and non-modules through customerspecific orders (Feldhusen and Grote, 2007).

Additive manufacturing processes can solve or at least mitigate such conflicts by making use of constructive freedoms. The potential of additive manufacturing includes the manufacturability of complex geometries and component-independent manufacturing processes (Petrovic et al., 2011; Gao et al., 2015; Hague et al., 2003). Through additive manufacturing, non-modules can be produced more effectively due to the shorter process chain.

Within the framework of the presented approach product developers are supported by the consideration of the product functions. In the following section the product and process models used in the context of the extended procedure are presented. The third section contains a detailed description of the extended procedure. This is based on the presented models and extends them by the systematic, specific consideration of additive manufacturing. The fourth section applies the procedure to an already modular product. The performance of the procedure is demonstrated and the changes to the product architecture and components are portrayed.

In the course of the section the following research questions are targeted and answered:

- How can the potential of additive manufacturing be optimally considered and used systematically and which stage of development is most suitable?

- How can optimization areas in complex product structures be systematically recognized and used?

- What influence does this have on the modular product structure?

\section{Fundamentals}

In this section the models and boundary conditions used for the extended procedure are outlined. For the comprehensive use of the potentials of additive manufacturing for the optimization of modular products an extended procedure model is presented. This model is based on the actions of the VDI 2221 Part 1. The VDI 2221 describes the product development process as a procedure usually from more abstract product and process models to more and more concrete models. The final outcome is the complete documentation of the production of the product. The actions of VDI 2221 are used as a reference for the product development process (VDI, 2018). In order to master the complexity, both the abstract view of the product architecture and the limitation of the area for which the extended procedure is carried out can be applied. Due to the immense number of interactions between the components and the large number of different variants, the systematic identification of optimization areas is of decisive importance. In order to consider the potentials of additive manufacturing, several levels of abstraction are necessary. In existing approaches this systematic integration is currently carried out on levels with more concrete models. An early consideration is particularly advantageous because it increases the depth of influence of additive manufacturing and the scope for action is particularly high. For the best possible usage the potentials have to be taken into account at the beginning of the product and process development. In order to anticipate the influences of additive manufacturing processes a great deal of experience is required in the build-up process and in upstream and downstream processes. During the product development process a large number of boundary conditions and interactions must be taken into account. These have their origin in the product life phases. The integrated product and process development model based on Birkhofer et al. (2018) is used to classify the various approaches and guidelines. This is shown in Figure 1 and illustrates the interactions between product development and the product life cycle. The functional product is created from material production to production and assembly. This passes through the utilisation phase. Finally, the product is to be recycled or disposed of. This chain of life cycle phases is influenced by product development and process development. Findings from the life cycle phases can be anticipated, for example by guidelines of the DfX approaches within the framework. They can be used during the development process. This model illustrates the possibility of influencing the life cycle phases of the 
product through product development and the anticipation of various information and restrictions from the various life cycle phases. The integrated product and process development according to Birkhofer et al. (2018) is used to link the extended procedure with the Design for X. Examples are the concepts design for additive manufacturing DfAM and design for mass customisation DfMC.

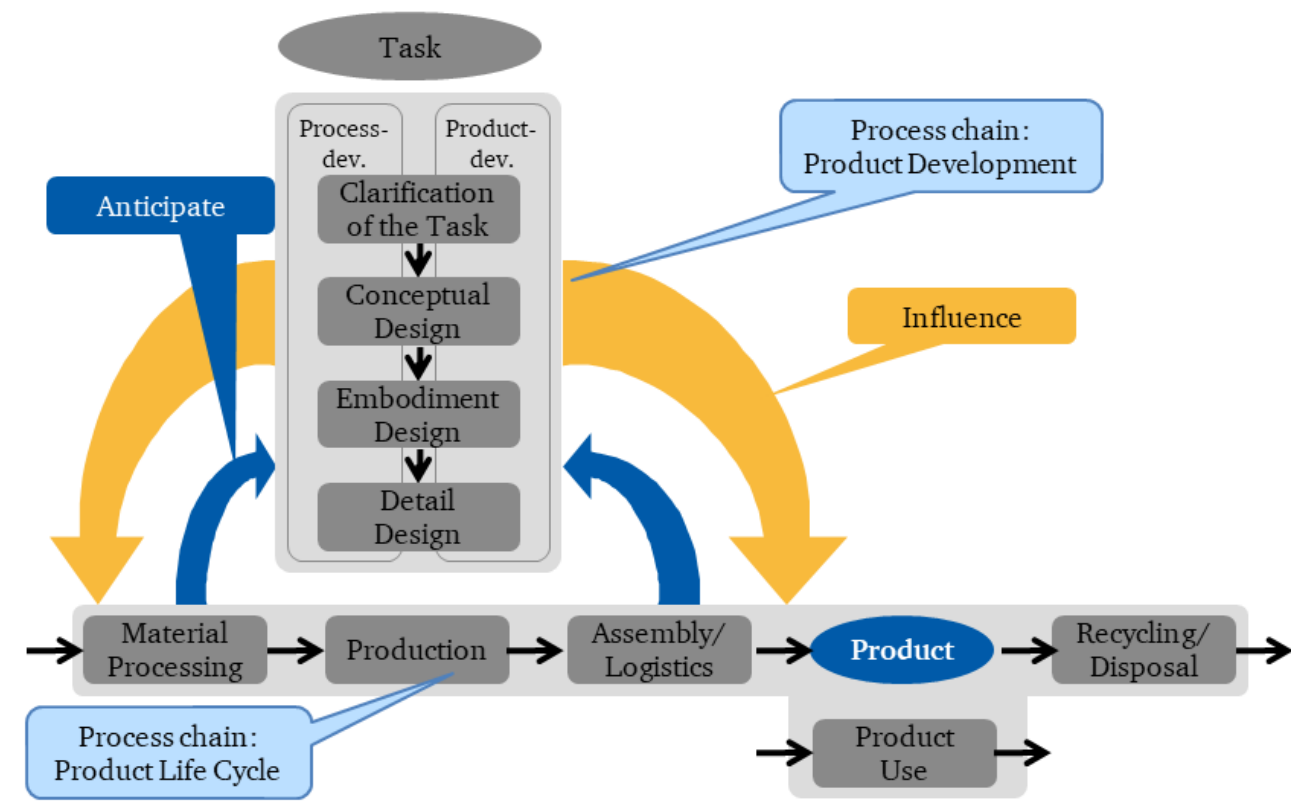

Figure 1. Integrated product and process development according to Birkhofer et al. (2018)

Modular product architectures are difficult to master due to their high complexity. Strategies for mastery are an abstract view and the delimitation of areas relevant for optimization. Thus, the functional consideration in form of a function structure as key element is suggested. Birkhofer (1980) is adduced as the basis for this. This is located on an abstraction level which is suitable for finding optimization areas.

For a model-based development of modular products the terms module and product variants are discussed below. A module is a component or assembly that is functionally and physically largely independent of the rest of the product. It has one or more standardized interfaces and can be combined with other modules (Westhäuser, 2014 in accordance to Arnoscht, 2011). Product variants are products with very similar form and/or function as well as the same purpose. They usually have a high proportion of identical groups or parts but differ in at least one property that is ideally relevant to the customer's purchasing decision so that they can select the appropriate product variant (Krause and Gebhardt, 2018). The entirety of the available modules form the modular system. The modular system allows to configure variants by combining modules. The Management Engineering Tool for Unified Systems from Göpfert is used to structure the product architecture and to support the definition of modules. This assumes that the functions of a product can be mapped to one or more components. A component can provide several functions. Both the functions and the components are interdependent. These can be described by the associated function and product structure (Göpfert, 1998). Additionally, their connections are represented and which functions are fulfilled by the different construction units. Items allocated to organizational units are highlighted in the same colour. Organizational units on the functional structure side define development activities while they are based on the product structure side to define production and assembly activities. An exemplary product architecture is shown in Figure 2.

Various authors developed combinatorial approaches to combine additive manufacturing and modularisation within the framework of mass customisation (Hague et al., 2003; Lei et al., 2015; Spallek et al., 2016; Spallek and Krause, 2016; Ko et al., 2015a, 2015b; Pereira et al., 2019; Oh et al., 2018; Deradjat and Minshall 2015, 2016, 2018; Reeves et al., 2011). As a rule these approaches are also limited to a sequential or parallel application of DfAM and DfMC methods. For further literature research, please refer to the work of Yang and Zhao (2015). 


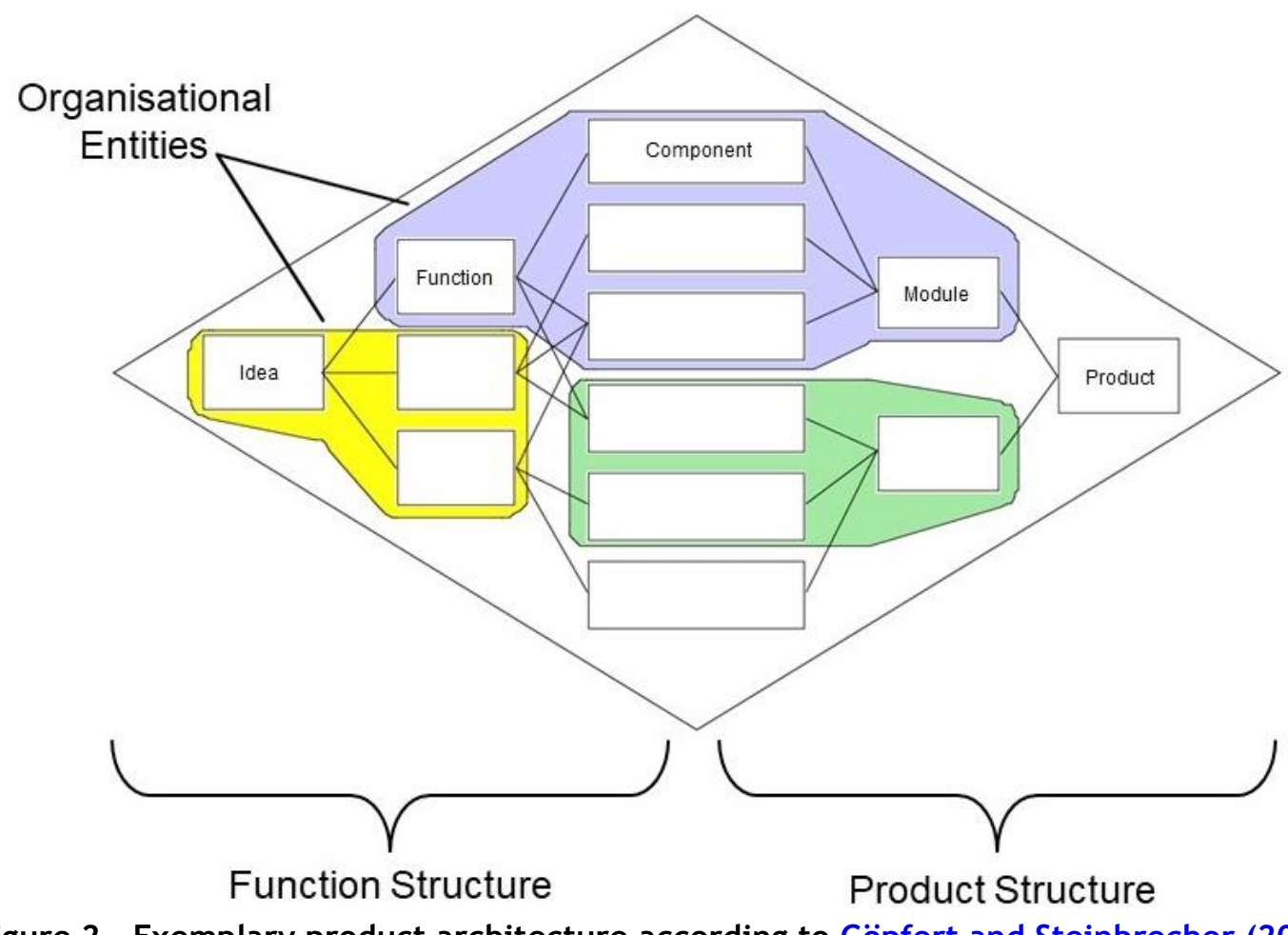

Figure 2. Exemplary product architecture according to Göpfert and Steinbrecher (2000)

\section{The extended approach}

The extended approach for the consideration of additive manufacturing processes for the optimization of modular products uses the structure of VDI 2221. Starting from a list of requirements the scope can be narrowed down strongly at the beginning by performing a strategic analysis, for example through the quality function deployment.

Following this, a function structure is created via a function analysis or -synthesis and may be optimized by a function variation if necessary. The function structure of the product is used to isolate relevant areas. For this purpose, unique functional characteristics of variants and customer specific functions are identified. Two possibilities can be used for the systematic search for promising optimization areas. These can be taken as variant drivers as described by Pahl and Beitz (Feldhusen and Grote, 2013).

- Variant specific optimization areas are function paths which only occur in certain variants and do not belong to the basic functions of all variants. In principle, these are suitable for additive manufacturing. Due to this, components that provide these functions are variants themselves. The function is not relevant for all customers.

- Individual optimisation areas can be identified on the basis of the input variables or the output variables. Variables that leave the system boundary are of particular interest. These can represent the interface to the customer and are particularly suitable for individualization. If a function is divisible in sub-functions the critical sub-function is further analysed. This continues until the suitable elementary functions are determined. If the function has different input and/or output variables for every customer occurs the function is suitable for the usage of additive manufacturing.

The suitable partial functions which were chosen with the variant drivers are carried to the search for the partial solutions. A systematic variation of working principles (Pahl et al., 2007; Feldhusen and Grote, 2013; Ponn and Lindemann, 2011) helps to find general partial solutions. Within the systematic variation AM is taken into account through a list of enriching AM-characteristics. This list can include the feasibility of local properties (e.g. material or density) or free-form shapes. 
The resulting partial solutions are added to a morphological analysis. Besides the variant-driving partial functions and AM-enriched partial solutions, the morphological box is supplemented with the remaining ordinary partial functions and solutions of the product which were not specifically considered for the use with AM. This applies to new and further developments. Through the application of AM new synergies become possible and are sought with this enlarged morphological box. Special attention is paid towards the functional integration of several partial functions. This functional integration can be realized, for example, through an integrational construction within the additive manufactured modules or with the integration of non-AM components (e.g. actuators or sensors).

After the combination of the partial solutions to principle solution variants, these are filtered through selection- and evaluation-methods. When applying the methods the already introduced enriching AM-characteristics are taken into account and enhanced by a list of AM based restrictions. The AM based restrictions include material- and design-limitations (e.g VDI 3405 Part 3, 2015).of the additive manufacturing. The whole design-process of the final product and its parts is supported by the presented enriching AM characteristics and AM restrictions. The step s of the approach are shown in Figure 3 and can be applied to develop a completely new product, design a modular product on base of an existing product or to further develop an existing modular product. This is a result through the universality of the basis of the VDI 2221 (VDI, 2018).

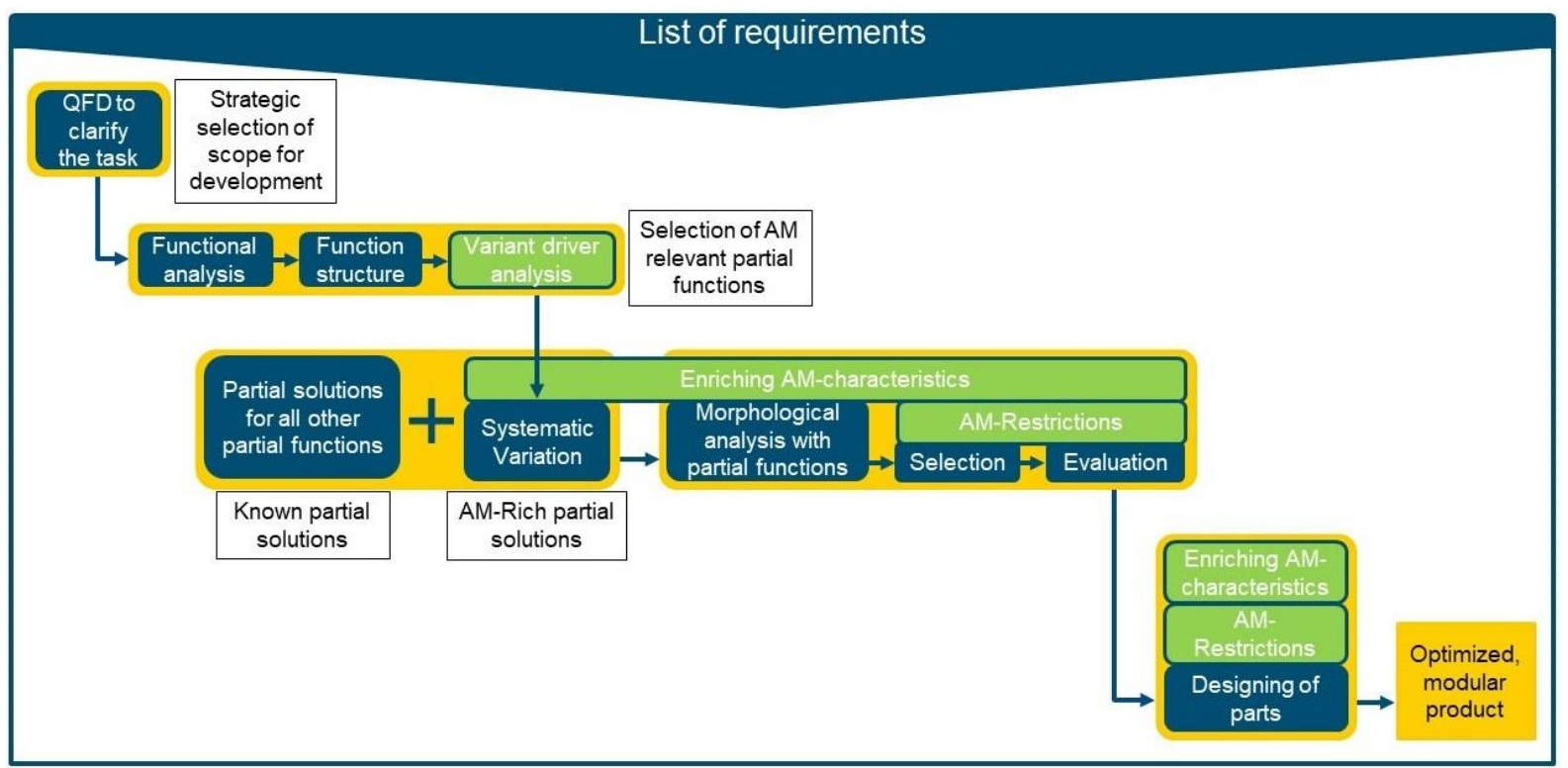

Figure 3. Extended approach for consideration of additive manufacturing processes in modular products

The resulting product combines the benefits of a modular product structure while minimizing its drawbacks. The enhanced extend of functional integration within the modules reduces the overall complexity. Furthermore, the additive manufacturing of variant driving function carriers allows the economically production of individualized customer products. This reduces the risk of oversizing or undersizing of standardized modules. In addition, additive manufactured products have a reduced process chain from production to logistics provision in comparison to externally manufactured components. This applies in particular to primary forming components. The process chain of the production tools remains the same due to tool-free production for individual or newly designed components. Furthermore, the provision of spare parts on request also benefits. This avoids high storage costs and reduces the influence of uncertainties in estimating which components will be needed in the following years. The targeted consideration of potentials enables to simplify or eliminate interfaces, reduce component-specific over- and undersizing and improve the benefit-effort ratio. The extended approach can be used with little to no experience with the usage of AM. 


\section{Example}

Companies strive to produce lightweight motorcycle helmets with divine wearing comfort. Latest helmets furthermore reveal a development trend towards integrated electronic devices, like headsets or radios. Modern helmets consist of multitude components with even more parts. Latest models from motorcycle-equipment brands like Shoei or Schuberth comprise between 7 and 15 components (Shoei, 2019; Schuberth, 2019). Withal the comfort padding is realized with up to seven independent paddings.

A large number of the components are due to the interchangeable und adaptable paddings. Nevertheless, only a limited extent of customization is offered, which leads to a suboptimal comfort of the individual customer.

To keep this example uncluttered a generic helmet gets reduced to three main modules as shown in Figure 4: Shell (contains 15 components inclusive visor), Protective Padding (only one single component) and Comfort Padding (contains five independent padding parts).

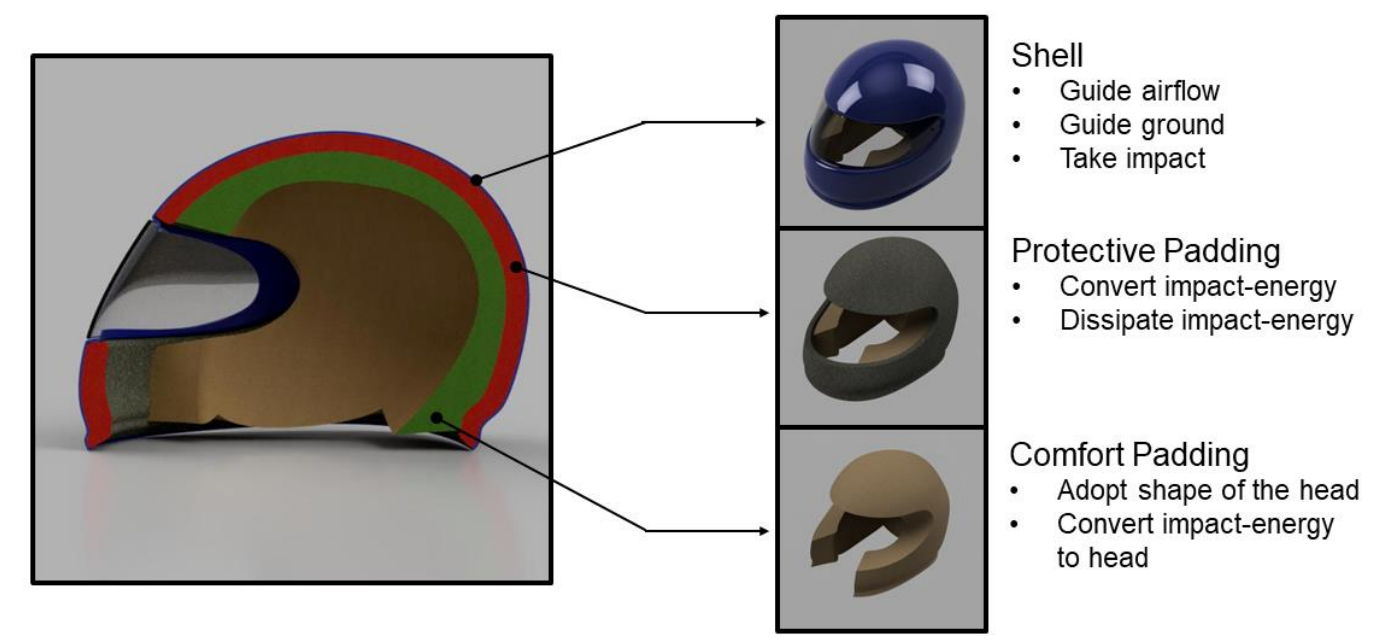

Figure 4. Components and their function of the generic helmet

In the following the generic and already modularized helmet shall be reworked. Besides an overall AM-optimisation the speed of the motorcycle has to be provided to the driver by project it directly onto the visor in form of a head-up display.

The generic helmet fulfils the functions of taking the impact, leading the energy, guide air and guide asphalt in case of an accident. The new designed helmet shall include the additional function showing information.

The functions of taking the impact and leading the energy as well as guiding the surrounding are the main functions of a helmet and important for every customer. On the contrary the function of showing information is not relevant for every customer and therefore suitable for the integration in an additive manufactured module.

By inspecting the input and output values of the functions it shows that the output of the function of leading the impact is different for every customer since the force leading surface is adapted to the form of the head. A deeper look into the function structure reveals that this refers to the subfunctions forming the energy from punctiform to quasi-spherical (form of the helmet) and forming the energy from quasi-spherical to the head shape. The information on the areas of input and output of the function are known through the analysis of the existing product.

For better understanding, the functions are transferred into a standardized description according to Birkhofer (1980). The function of taking the impact corresponds the conversion of kinetic energy from punctiform to a quasi-spherical surface (form of the helmet). The function leading the energy is equivalent to a conversion of the kinetic energy from the quasi-spherical surface to a head shaped form. Furthermore, energy gets dissipated which transforms a portion from the kinetic energy to thermic energy. Guide air and guide asphalt is represented with the guidance of the surrounding. To show information, the needed electric energy is stored in a storage unit. If 
required, this electric energy is coupled with an information-signal about the speed and converted into an optical signal. The connections of the inputs and outputs of the partial functions are shown in Figure 5. Sub-functions that are followed up are framed in colour.

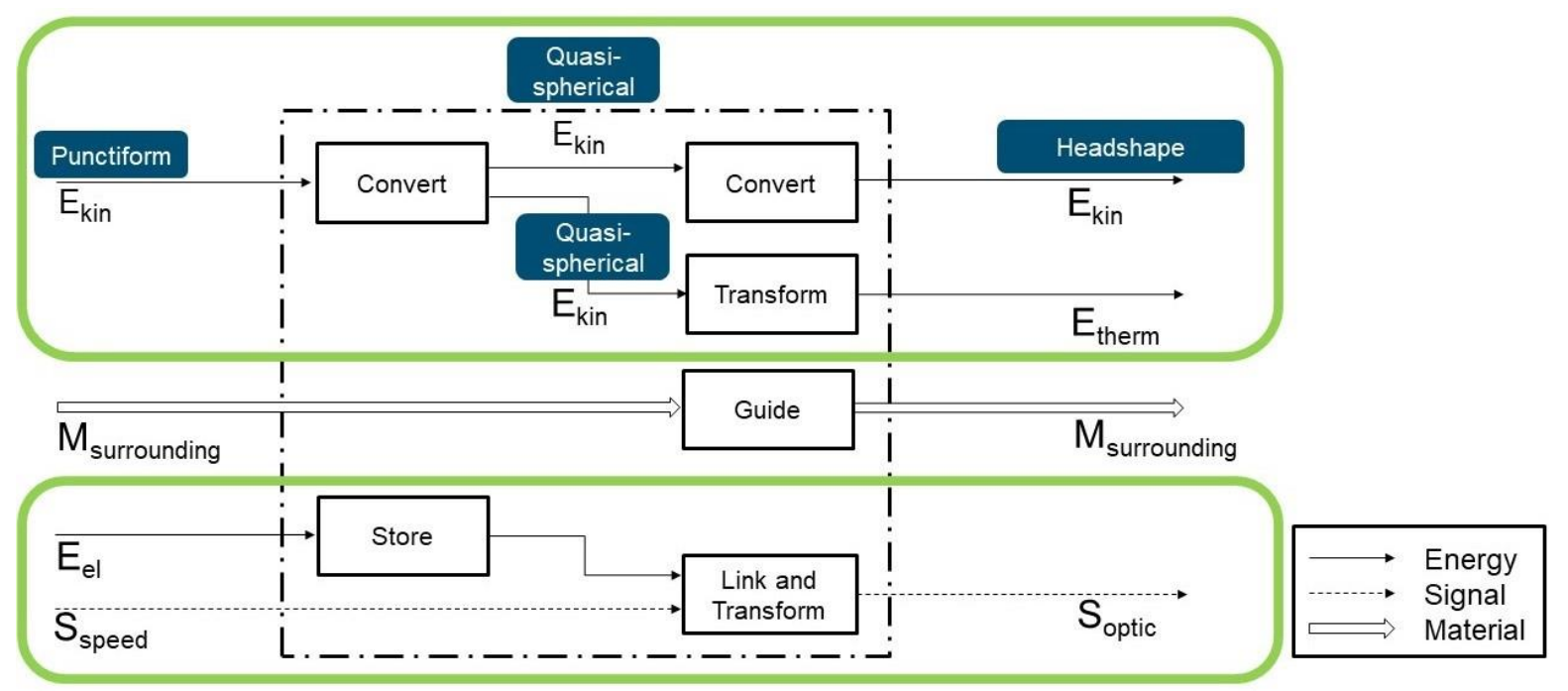

Figure 5. Function structure of the generic Helmet in standardized description

The partial solutions in this example are not determined by a complete systematic variation of working principles but by a reference to existing helmets. Nevertheless, these partial solutions are analysed considering the enriching AM-characteristics. One design potential of additive manufacturing is the manufacturability of free-form shapes like lattice structures. The "convert" functions can be achieved by partial solutions which gain their flexibility from these lattice structures. The partial function showing information does not show an explicit AM suitable partial solution, except for the possible integration of components.

The AM-suitable partial functions and the AM-rich partial solutions are carried over in a morphological box. It further contains the rest of the partial functions and partial solutions, which don't show any explicit potential with AM. While combining the partial solutions to principle solution variants, the new AM-specific synergy effects should be considered. These are also enriching AM-characteristics and contains the functional integration either through local properties like flexibility (through a lattice structure with thickness gradients of the joists) or through the integration of non-AM components. This results in a single padding, which can fulfil both functions taking the impact and leading the energy. Furthermore, an easy integration of electronic components into this padding is recognized. Figure 6 shows the change in the product structures of the helmet (according to Göpfert ) due to the optimization. The summary of several components and modules becomes apparent, along with a simplification of the related organizational entity. Selection- and evaluation-methods (also supported with lists of enriching AM-characteristics and AM-Restrictions) are applied in order to find the most suitable variant.

The whole design-process of the final product and its parts is performed as usual but supported by lists of the enriching AM-characteristics and AM-Restrictions. In this design process it gets clear that the economically manufacturing of single products allows for customer individualized paddings.

The resulting helmet stands out through a single padding part, including a lattice structure with thickness gradients of the joists. The thicker joists on the outside have protective purpose. The thinner joists are softer and provide more comfort. This lattice structure leads to a weight reduction and the padding can be economical individualized for single customers. This increases the wearing comfort and enables a more even transmission from the energy which leads to more safety. The uncomplicated integration of modules into the padding allows the individual choice of whether a head-up module should be installed.

The result is shown in Figure 7 as a prototype on a scale of 1: 2.5. 


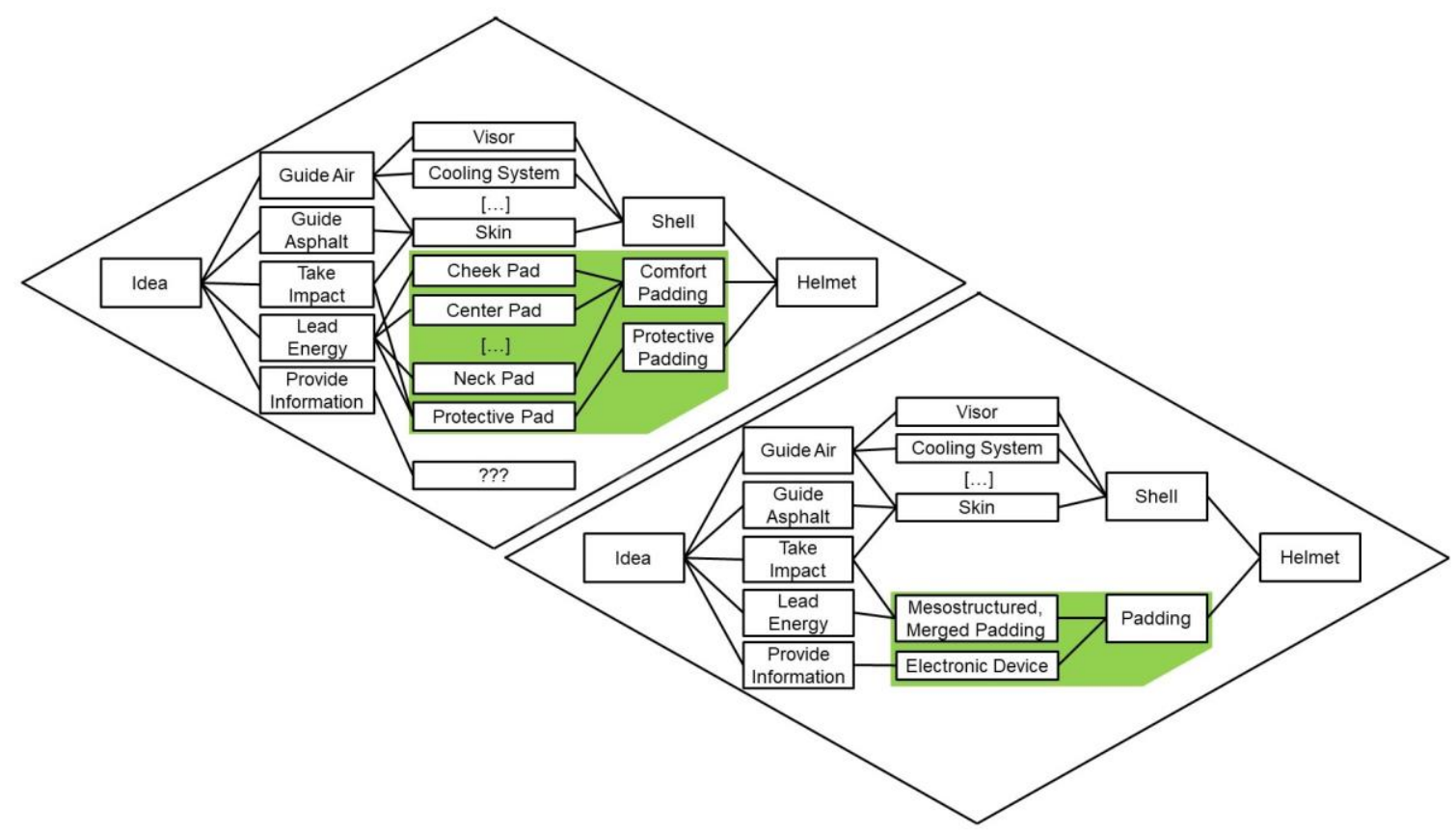

Figure 6. Product architecture of the optimized helmet

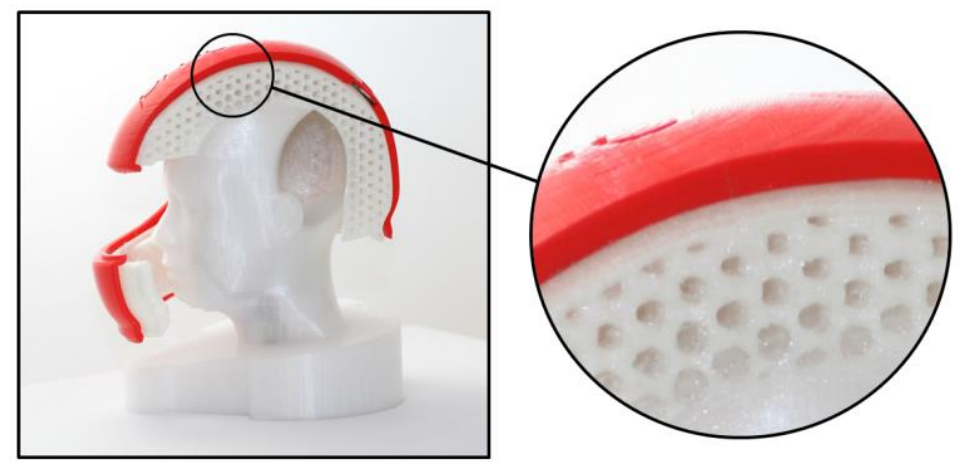

Figure 7. Prototype of the optimized, generic helmet

Besides an optimized helmet design, the deployment of additive manufacturing shows potential in organisational aspects. The reduced part number results in reduced intern complexity and storage costs. Furthermore, the interfaces are reduced which shorten the overall assembly process. The manufacturability on location and on demand results in a shorter time-to-market (Petrovic et al., 2011; Gao et al., 2015). This distresses the whole supply- and process-chain.

\section{Conclusion}

In modular products conflicting objectives can occur for example through standardization. These conflicting objectives lead to characteristics like component-dependent over- and undersizing. Furthermore, complex interfaces occur in order to enable the use of components across variants. The additive manufacturing processes are suitable for mitigating and resolving these conflicting objectives. To use the potentials of additive manufacturing their consideration in the early phases of the product development process is most suitable. This increases the depth of the possible courses of action. The current approaches to consider additive manufacturing provide support for the developer on more concrete levels. For this reason, an extended approach is presented which enables a systematic consideration of additive manufacturing already from the functional level using an analysis method for the function structure. The developer is supported by the method of the systematic search of variant drivers by two characteristics. This method supports the delimitation of areas through identifying selections of partial functions which in principle are suitable for an optimization by AM. This this is 
achieved through the targeted identification of functions to which different customers have different boundary conditions. Partial solutions are subsequently determined for this selection of relevant sub functions. Thus, the solution field is decisively extended. The extended approach is applied to a customizable generic motorcycle helmet for further development. The helmet is already a modular product. The results of the approach lead to an optimized product structure, optimized components and organizational aspects and an individualized modular product. The resulting helmet has fewer modules with more integrated functions. This results in a less complex product structure. Furthermore, it is possible to individualize the helmet for each customer without a significant increase of cost. The extended approach thus leads to an improved utilization of the potentials of additive manufacturing and to a multitude of new possibilities for the optimization of modular products. In the course of further research, the application of the extended procedure has to be applied on a new development of modular products, on an existing product to be modularized as well as on a modular product with a higher number of interactions.

\section{References}

Arnoscht, J. (2011), Beherrschung von Komplexität bei der Gestaltung von Baukastensystemen, ApprimusVerlag, Aachen.

Birkhofer, H. (1980), Analyse und Synthese der Funktionen technischer Produkte [Dr.-Ing. Thesis], Fakultät für Maschinenbau und Elektrotechnik der Technischen Universität Carolo- Wilhelmina zu Braunschweig.

Birkhofer, H. et al. (2018), “Umweltgerechtes Konstruieren”, In: Rieg, F. and Steinhilper, R. (Eds.), Handbuch Konstruktion, Carl Hanser Verlag, München, pp. 601-622. http://dx.doi.org/10.3139/9783446456198

Deradjat, D. and Minshall, T. (2015), "Implementation of additive manufacturing technologies for mass customisation", IAMOT 2015 Conference Proceedings, Cape Town, South Africa, 8-11 June, 2015, IAMOT, pp. 2079-2094.

Deradjat, D. and Minshall, T. (2016), "Implementation of Rapid Manufacturing for Mass Customisation”, Journal of Manufacturing Technology Management, Vol. 28, pp. 95-121. https://doi.org/10.17863/CAM.4528

Deradjat, D. and Minshall, T. (2018), "Decision trees for implementing rapid manufacturing for mass customisation", CIRP Journal of Manufacturing Science and Technology, Vol. 23, pp. 156-171. https://doi.org/10.1016/ j.cirpj.2017.12.003

Feldhusen, J. and Grote, K. (2007), Pahl/ Beitz Konstruktionslehre, Springer, Berlin.

Feldhusen, J. and Grote, K (2013), "Grundsätzliche Arbeitsschritte beim Entwickeln und Konstruieren", In: Feldhusen, J. and Grote, K. (Eds.), Pahl/Beitz Konstruktionslehre, Springer, Berlin, pp. 283-290. http://doi.org/10.1007/978-3-642-29569-0

Gao, W. et al. (2015), “The status, challenges, and future of additive manufacturing in engineering”, ComputerAided Design, Vol. 69, pp. 65-89. https://doi.org/10.1016/j.cad.2015.04.001

Göpfert, J. (1998), Modulare Produktentwicklung: zur gemeinsamen Gestaltung von Technik und Organisation, Deutscher Universitätsverlag, Wiesbaden.

Göpfert, J. and Steinbrecher, M. (2000), "Modulare Produktentwicklung leistet mehr", Harvard Business Manager, Vol. 3, pp. 20-31.

Hague, R., Campbell, I. and Dickens, P. (2003), "Implications on design of rapid manufacturing", Proceedings of the Institution of Mechanical Engineers Part C Journal of Mechanical Engineering Science, Vol. 217 No. 1, pp. 25-30. https://doi.org/10.1243/095440603762554587

Kipp, T., Blees, C. and Krause, D. (2010), “Anwendung einer integrierten Methode zur Entwicklung modularer Produktfamilien”, DFX 2010: Proceedings of the 21st Symposium on Design for X, Buchholz/Hamburg, Germany, September 23-24, 2010, TuTech Innovation GmbH, Hamburg, pp. 157-168.

Ko, H., Moon, S. and Hwang, J. (2015a), "Design for additive manufacturing in customized products", International Journal of Precision Engineering and Manufacturing, Vol. 16 No. 11, pp. 2369-2375. https://doi.org/10.1007/s12541-015-0305-9

Ko, H., Moon, S. and Otto, K. (2015b), "Design knowledge representation to support personalised additive manufacturing", Virtual and Physical Prototyping, Vol. 10 No. 4, pp. 217-226. https://doi.org/10.1080/1745 2759.2015.1107942

Krause, D. and Gebhardt, N. (2018), Methodische Entwicklung modularer Produktfamilien: Hohe Produktvielfalt beherrschbar entwickeln, Springer, Berlin. http://dx.doi.org/10.1007/978-3-662-53040-5

Lei, N., Moon, S. and Rosen, D. (2015), "Redefining Product Family Design for Additive Manufacturing", 20th International Conference on Engineering Design, Milano, Italy, 27-30 July, 2015, Nanyang Technological University, Singapore, pp. 267-278. https://doi.org/10.1007/s12541-015-0305-9 
Lissautzki, M. (2008), Kundenwertorientierte Unternehmenssteuerung: Voraussetzungen, Aufgaben, Werttreiberanalysen, Deutscher Universitäts-Verlag | GWV Fachverlage GmbH, Wiesbaden. http://doi.org/ 10.1007/978-3-8350-5473-8

Oh, Y., Zhoe, C. and Behdad, S. (2018), "Production Planning for Mass Customization in Additive Manufacturing: Build Orientation Determination, 2D Packing and Scheduling", Proceedings of the ASME 2018 International Design Engineering Technical Conferences, Quebec, Canada, August 26-28, 2018, ASME. https://doi.org/10.1115/DETC2018-85639

Pahl, G. et al. (2007), Engineering Design, Springer, London. https://doi.org/10.1007/978-1-84628-319-2

Pereira, T., Kennedy, J. and Potgieter, J. (2019), "A comparison of traditional manufacturing vs additive manufacturing, the best method for the job", Procedia Manufacturing, Vol. 30, pp. 11-18. https://doi.org/10. 1016/j.promfg.2019.02.003

Petrovic, V. et al. (2011), "Additive layered manufacturing: sectors of industrial application shown through case studies”, International Journal of Production Research, Vol. 39 No. 4, pp. 1061-1079. https://doi.org/ $10.1080 / 00207540903479786$

Ponn, J. and Lindemann, U. (2011), Konzeptentwicklung und Gestaltung technischer Produkte, Springer, Berlin. https://doi.org/10.1007/978-3-642-20580-4

Reeves, P., Tuck, C. and Hague, R. (2011), “Additive Manufacturing for Mass Customization”, In: Fogliatto, F. and da Silveira, G. (Eds.), Mass Customization, Springer, London, pp. 275-290. https://doi.org/10.1007/9781-84996-489-0

Schuberth (2019), C4-Basic Manual. [online] Schuberth GmbH. Available at: https://www.schuberth.com/ fileadmin/content/documents/Manuals_MOT/MANUAL_C4_Basic_DE.pdf (accessed 05.11.2019)

Shoei (2019), X-Fourteen-X-Spirit III Manual. [online] Shoei co. ltd. Available at: http://www.shoeieurope.com/upload/manuals/X-Fourteen-X-Spirit_III_100P-small.pdf (accessed 05.11.2019)

Spallek, J. and Krause, D. (2016), "Process Types of Customisation and Personalisation in Design for Additive Manufacturing Applied to Vascular Models", Procedia CIRP, Vol. 50, pp. 281-286. https://doi.org/10.1016/ j.procir.2016.05.022

Spallek, J., Sankowski, O. and Krause, D. (2016), "Influences of Additive Manufacturing on Design Processes for Customised Products", 14th International Design Conference, Dubrovnik, Croatia, May 16-19, 2016, The Design Society, Glasgow, pp. 513-522. https://doi.org/10.13140/RG.2.1.1112.4080

VDI (2015), VDI 3405, Blatt 3: Additive Fertigungsverfahren, Konstruktionsempfehlungen für die Bauteilfertigung mit Laser-Sintern und Laser-Strahlschmelzen, Verein Deutscher Ingineure e.V., Düsseldorf.

VDI (2018), VDI 2221, Blatt 1: Entwicklung technischer Produkte und Sytseme - Modell der Produktentwicklung, Verein Deutscher Ingineure e.V., Düsseldorf.

Westhäuser, B. (2014), Methodik zur Entwicklung modularer Produkte und ihre Potentiale in Bezug auf den Einsatz im Robust Design [Master Thesis], TU Darmstadt.

Yang, S. and Zhao, Y. (2015), "Additive manufacturing-enabled design theory and methodology: a critical review”, The International Journal of Advanced Manufacturing Technology, Vol. 80 No. 1, pp. 327-342. https://doi.org/10.1007/s00170-015-6994-5 